\title{
Structure of Tetrakis(melaminium) Bis(dihydrogenphosphate) Monohydrogenphosphate Trihydrate from X-ray Powder Diffraction and Solid-State NMR Spectroscopy
}

\author{
Vladimir Brodski, René Peschar,* and Henk Schenk \\ Universiteit van Amsterdam, van't Hoff Institute for Molecular Sciences, Laboratory for Crystallography, \\ Valckenierstraat 65, NL-1018XE Amsterdam, The Netherlands

\begin{abstract}
Andreas Brinkmann, Ernst R. H. van Eck, and Arno P. M. Kentgens
Radboud University Nijmegen, Physical Chemistry/Solid State NMR, Institute for Molecules and Materials, Toernooiveld 1, NL-6525 ED Nijmegen, The Netherlands
\end{abstract}

Received: March 6, 2008; Revised Manuscript Received: June 3, 2008

\begin{abstract}
The crystal structure of the melamine phosphate salt tetrakis(melaminium) bis(dihydrogenphosphate) monohydrogenphosphate trihydrate with as much as ten independent moieties in the unit cell was determined by a direct-space global optimization technique from X-ray powder diffraction data using additional geometry constraints obtained by ${ }^{31} \mathrm{P}$ double-quantum solid-state NMR spectroscopy. The structure analysis of the compound and its comparison with other melamine phosphates reveals the packing and bonding characteristics that are important for melamine-phosphate salts with a melamine-to-phosphor ratio larger than one, which are promising environmental-friendly flame retardants.
\end{abstract}

\section{Introduction}

Reduction of flammability of polymers is commonly achieved by admixing flame retardants. Melamine phosphates are considered to be attractive alternatives to halogen-containing flameretardants because the latter release toxic and corrosive gases during combustion. The advantages of the flame-retardant characteristics of melamine phosphates materials are mainly attributed to an enhanced thermal stability, ${ }^{1}$ so an elucidation of their packing characteristics is particularly important.

Recently, we have successfully applied a combined approach of X-ray powder diffraction (XRPD), solid-state NMR, and Rietveld refinement to the structure determination of a series of melamine phosphates, with a melamine-to-phosphor (M:P) molar ratio of 1.0: melamine orthophosphate (MP), ${ }^{2}$ melamine pyrophosphate (MPy), ${ }^{3}$ and melamine polymethaphosphate (MPoly). ${ }^{4}$ One- and two-dimensional high-resolution solid-state ${ }^{1} \mathrm{H}$ NMR was used at high external magnetic field in combination with fast magic-angle-spinning of the sample to gain detailed information about the proton positions, proximities, and the hydrogen bonding network in MP. ${ }^{5}$ In addition, we determined the geometry of the $\mathrm{NH}$ and $\mathrm{NH}_{2}$ groups in MP by ${ }^{15} \mathrm{~N}-{ }^{1} \mathrm{H}$ heteronuclear recoupling experiments and could show that these geometries can only be convincingly obtained by solid-state NMR. ${ }^{5}$ An analysis of these and other melaminecontaining compounds revealed common packing characteristics and details of the dehydration mechanisms in the condensation route $\mathrm{MP} \rightarrow \mathrm{MPy} \rightarrow$ MPoly.

In a continuation of this work, we report here the structure of the melamine phosphate compound tetrakis(melaminium) bis(dihydrogenphosphate) monohydrogenphosphate trihydrate (from now on abbreviated as $\mathrm{M}_{4} \mathrm{P}_{3} \cdot 3 \mathrm{H}_{2} \mathrm{O}$ ). Both $\mathrm{M}_{4} \mathrm{P}_{3} \cdot 3 \mathrm{H}_{2} \mathrm{O}$ and its dehydrates have a M:P ratio $>1$, a characteristic of the latest generation of melamine phosphates that is used in flameretardant applications. ${ }^{1} \mathrm{M}_{4} \mathrm{P}_{3} \cdot 3 \mathrm{H}_{2} \mathrm{O}$ has 54 non-hydrogen atoms

* To whom correspondence should be addressed. E-mail: rene@ science.uva.nl. (or 93 atoms including hydrogens) in the asymmetric part of the unit cell or, when being approximated by 10 independent moieties, 51 degrees of freedom (DOF). Structure determination of a compound with so many DOF is a task that is on the very edge of the current abilities of modern direct-space XRPD structure-determination algorithms, ${ }^{6-8}$ and far from routine, but with the additional complementary information provided by oneand two-dimensional ${ }^{31} \mathrm{P}$ solid-state $\mathrm{NMR}^{9,10}$ the goal of determining the structure of $\mathrm{M}_{4} \mathrm{P}_{3} \cdot 3 \mathrm{H}_{2} \mathrm{O}$ was achieved.

\section{Experimental Section}

Synthesis. An aqueous solution of melamine (10.25 g, 0.0813 $\mathrm{mol}$ ) and phosphoric acid (7.22 g, $0.0737 \mathrm{~mol}$; purity $85 \%$ ) was heated and kept for $30 \mathrm{~min}$ at a minimum temperature of $75^{\circ} \mathrm{C}$ under continuous stirring. Slow cooling of the mixture to room temperature yielded crystals (white powder) that were filtrated and dried in a vacuum oven at $60{ }^{\circ} \mathrm{C}$ for $24 \mathrm{~h}$. The structure determination by means of XRPD established the crystal composition to be $\mathrm{M}_{4} \mathrm{P}_{3} \cdot 3 \mathrm{H}_{2} \mathrm{O}$.

X-ray Powder Diffraction Analysis. A high-resolution XRPD pattern was recorded at beamline BM01B of the SwissNorwegian CRG at the European Synchrotron Radiation Facility (ESRF, Grenoble) with a fixed wavelength of $0.75003 \AA$ at room temperature $(T \sim 295 \mathrm{~K})$. Data collection was carried out in a continuous scan mode from 3.03 to $42.26^{\circ} 2 \theta$ using a filled capillary (diameter $1.5 \mathrm{~mm}$ ) that was rotated during exposure. After data collection the scan was binned at $0.005^{\circ} 2 \theta$. In order to investigate preferred orientation, in-house experiments have been performed with an X-Pert One diffractometer (PANanalytical, Almelo, The Netherlands) in the reflection mode using $\mathrm{Cu} \mathrm{K \alpha}$ radiation. For these experiments samples with a significant preferred orientation were prepared by making a slurry with ethanol, putting it uniformly at the sample holder, and letting the ethanol evaporate. For indexing, the program ITO $^{11}$ was used. Structure determination was carried out with the program Organa. ${ }^{12 b}$ Rietveld refinement was carried out with the program GSAS. ${ }^{13}$ 


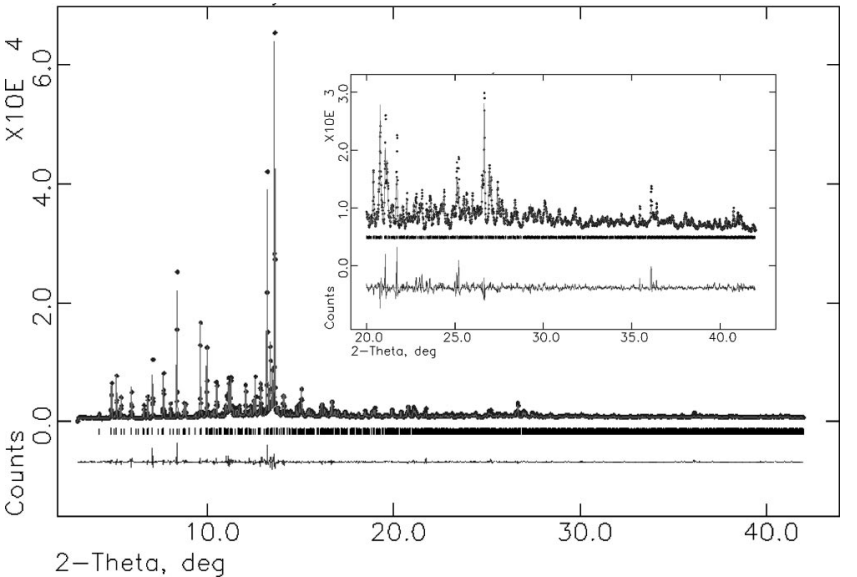

Figure 1. Synchrotron powder diffraction patterns of $\mathrm{M}_{4} \mathrm{P}_{3} \cdot 3 \mathrm{H}_{2} \mathrm{O}$ : experimental pattern (dots), the final calculated pattern after refinement (line), the calculated background and the difference (experimental calculated) pattern.

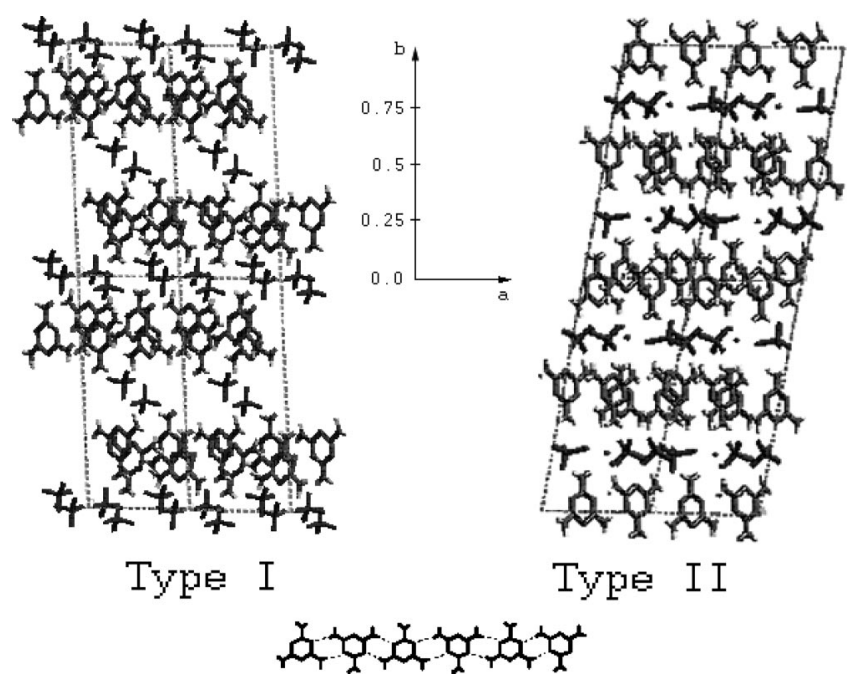

Figure 2. Two types of packing in $\mathrm{M}_{4} \mathrm{P}_{3} \cdot 3 \mathrm{H}_{2} \mathrm{O}$ found during the structure determination process and a fragment of the infinite melamine ribbon as present in the melamine layers of both packing types.

Solid-State NMR Spectroscopy. The ${ }^{31} \mathrm{P}$ cross-polarization magic-angle-spinning (CP-MAS) spectra of $\mathrm{M}_{4} \mathrm{P}_{3} \cdot 3 \mathrm{H}_{2} \mathrm{O}$ in Figure 3 were acquired at a static field of $7.05 \mathrm{~T}$ (Chemagnetics Infinity console and $2.5 \mathrm{~mm}$ Bruker HX MAS probehead) and sample spinning frequencies of 4.0 and $12.0 \mathrm{kHz}$ using a $\mathrm{CP}$ contact time of $1.5 \mathrm{~ms}$. TPPM decoupling ${ }^{14}$ with a ${ }^{1} \mathrm{H}$ nutation frequency of $100 \mathrm{kHz}$, pulse durations of $5.3 \mu \mathrm{s}$ and radiofrequency phases of $\pm 25^{\circ}$ were used during acquisition in both cases. The two-dimensional (2D) ${ }^{31} \mathrm{P}$ double-quantum (2Q) spectrum in Figure 5 was acquired at the same static field and spinning frequency using the homonuclear dipolar recoupling sequence SC14. ${ }^{10}$ The $2 \mathrm{Q}$ excitation and reconversion time periods were both $667 \mu \mathrm{s}$. The $\mathrm{CP}$ contact time was set to 1.2 ms. The evolution interval $t_{1}$ of the ${ }^{31} \mathrm{P}$ double-quantum coherences (2QC) was incremented in steps of $80 \mu \mathrm{s}$, in total 64 points were acquired in the $t_{1}$ dimension. Continuous wave decoupling was used during the SC14 sequence with a ${ }^{1} \mathrm{H}$ nutation frequency of $120 \mathrm{kHz}$. TPPM decoupling was applied during the evolution interval $t_{1}$ and acquisition with a ${ }^{1} \mathrm{H}$ nutation frequency of $100 \mathrm{kHz}$, pulse durations of $5.3 \mu \mathrm{s}$ and radiofrequency phases of $\pm 15^{\circ}$. The signal in the $t_{1}$ dimension was apodized with a squared cosine function and converted into the frequency domain $\left(\omega_{1}\right)$ using a cosine Fourier transform. The

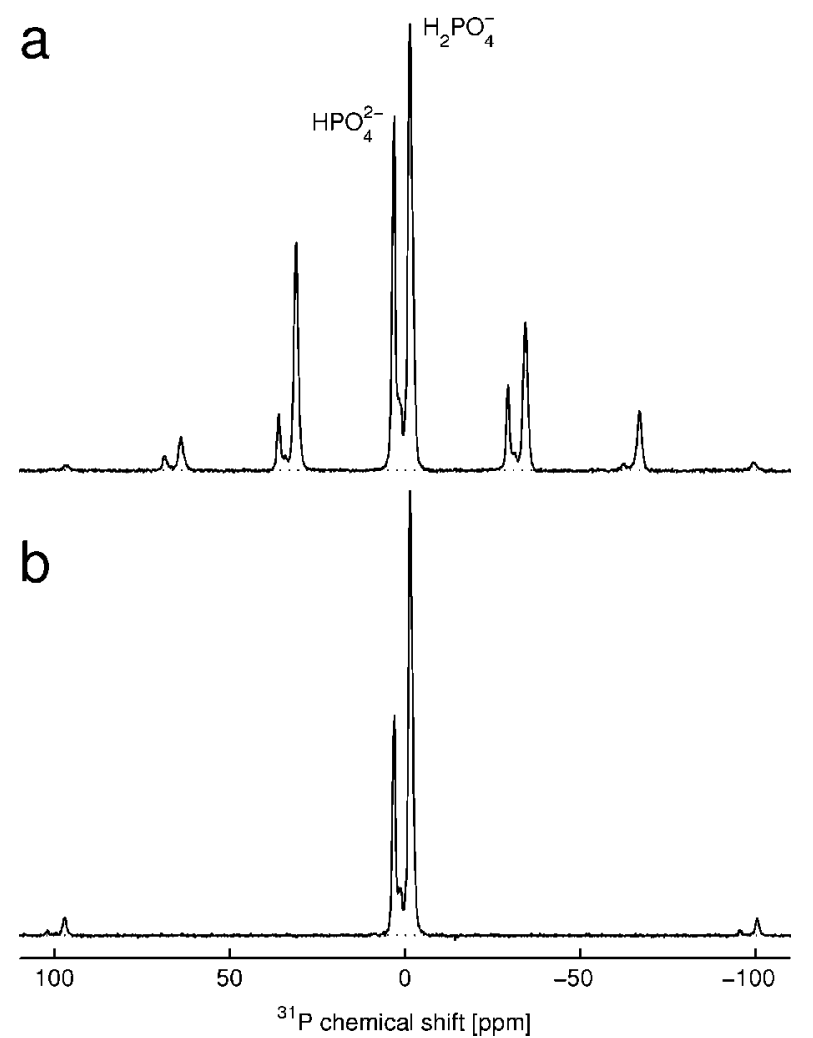

Figure 3. ${ }^{31} \mathrm{P} \mathrm{CP}-\mathrm{MAS}$ spectra of $\mathrm{M}_{4} \mathrm{P}_{3} \cdot 3 \mathrm{H}_{2} \mathrm{O}$ at a spinning frequency of (a) 4 and (b) $12 \mathrm{kHz}$. In (a) the centerbands stemming from the P61 and P66/71 sites are labeled. The sidebands of both sites are not labeled. A third line of low intensity can be seen, indicating the presence of a small impurity phase, as was also observed in the XRPD.

TPPI scheme ${ }^{15}$ was used to obtain pure absorption peaks in the $2 \mathrm{D}$ spectrum and to distinguish positive and negative spectral frequencies in the $\omega_{1}$ dimension. The experimental single-pulse ${ }^{1} \mathrm{H}$ MAS spectra shown in Figure 4a was recorded at a static field of $18.8 \mathrm{~T}$ (Chemagnetics Infinity+ console and $1.8 \mathrm{~mm}$ home-built probe head employing a Samoson stator ${ }^{16}$ ) and a sample spinning frequency of $48.0 \mathrm{kHz}$. The experimental 2D ${ }^{1} \mathrm{H}-{ }^{31} \mathrm{P}$ heteronuclear correlation (HETCOR) ${ }^{17}$ spectrum shown in Figure $4 \mathrm{~b}$ was acquired at a static field of $7.05 \mathrm{~T}$ and a spinning frequency of $12 \mathrm{kHz}$. During the ${ }^{1} \mathrm{H}$ evolution time interval $t_{1}$ frequency-switched Lee-Goldburg (FSLG) ${ }^{18}$ homonuclear decoupling was applied and the ${ }^{1} \mathrm{H}$ magnetization was transferred to the ${ }^{31} \mathrm{P}$ spins by Lee-Goldburg CP (LG-CP). ${ }^{19}$ The FSLG decoupling used a ${ }^{1} \mathrm{H}$ nutation frequency of $100 \mathrm{kHz}$ and frequency jumps of $\pm 70.711 \mathrm{kHz}$ with an overall offset of $-1.5 \mathrm{kHz}$. The frequency jumps were performed with a simultaneous $180^{\circ}$ phase shift every $8.6 \mu$ s. During LG-CP the ${ }^{1} \mathrm{H}$ nutation frequency was $100 \mathrm{kHz}$ and the rf frequency offset was $70.711 \mathrm{kHz}$. The cross polarization interval was $0.1 \mathrm{~ms}$. TPPM decoupling with a ${ }^{1} \mathrm{H}$ nutation frequency of $100 \mathrm{kHz}$, pulse duration of $5.3 \mu \mathrm{s}$ and $\mathrm{rf}$ phases of $\pm 25^{\circ}$ was applied during signal detection. The delay between experiments was $5 \mathrm{~s}$. The experimental $2 \mathrm{D}{ }^{1} \mathrm{H}-{ }^{15} \mathrm{~N}$ HETCOR spectrum shown in Figure $4 \mathrm{c}$ was acquired at a static field of $18.8 \mathrm{~T}$ and a spinning frequency of $48 \mathrm{kHz}$. The ${ }^{1} \mathrm{H}$ transverse magnetization evolved freely in the $t_{1}$ dimension and was transferred to the ${ }^{15} \mathrm{~N}$ spins by conventional $\mathrm{CP}$ with a contact interval of $2 \mathrm{~ms}$. Low power continuous-wave decoupling with a ${ }^{1} \mathrm{H}$ nutation frequency of 6 $\mathrm{kHz}$ was applied during the detection of the ${ }^{15} \mathrm{~N}$ signal. 


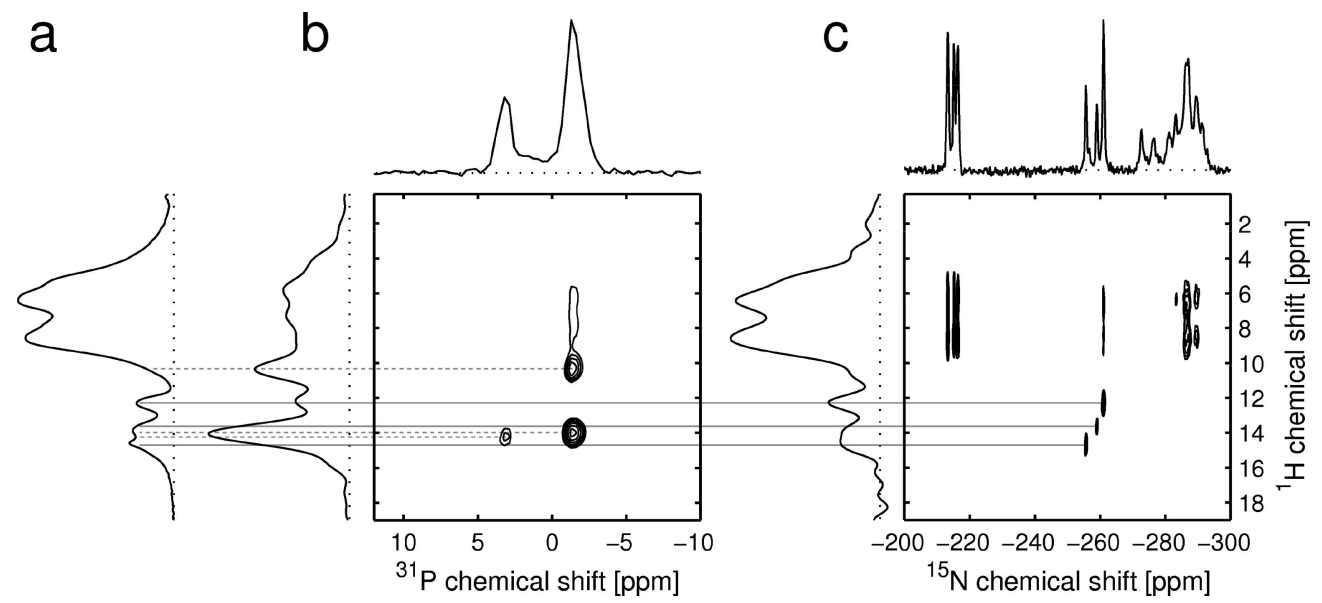

Figure 4. (a) Single-pulse ${ }^{1} \mathrm{H}$ spectrum of $\mathrm{M}_{4} \mathrm{P}_{3} \cdot 3 \mathrm{H}_{2} \mathrm{O}$ obtained at $18.8 \mathrm{~T}$ and $48.0 \mathrm{kHz}$ MAS. (b) Experimental $2 \mathrm{D}{ }^{1} \mathrm{H}-{ }^{31} \mathrm{P}$ correlation spectrum of $\mathrm{M}_{4} \mathrm{P}_{3} \cdot 3 \mathrm{H}_{2} \mathrm{O}$ obtained at $7.05 \mathrm{~T}$ and $12 \mathrm{kHz}$ MAS frequency, where FSLG homonuclear decoupling was applied in the indirect $t_{1}$ dimension. The ${ }^{1} \mathrm{H}$ magnetization was transferred to the ${ }^{31} \mathrm{P}$ spins by LG-CP with a cross polarization interval of $0.1 \mathrm{~ms}$. (c) Experimental $2 \mathrm{D}{ }^{1} \mathrm{H}-{ }^{15} \mathrm{~N}$ correlation spectrum of $\left[\mathrm{U}-{ }^{15} \mathrm{~N}\right]-\mathrm{M}_{4} \mathrm{P}_{3} \cdot 3 \mathrm{H}_{2} \mathrm{O}$ obtained at $18.8 \mathrm{~T}$ and $48.0 \mathrm{kHz}$ MAS, where the ${ }^{1} \mathrm{H}$ transverse magnetization evolved freely in the $t_{1}$ dimension. The ${ }^{1} \mathrm{H}$ magnetization was transferred to the ${ }^{15} \mathrm{~N}$ spins by conventional $\mathrm{CP}$ with a contact interval of $2 \mathrm{~ms}$.

TABLE 1: Crystallographic Data of $\mathrm{M}_{4} \mathrm{P}_{3} \cdot 3 \mathrm{H}_{2} \mathrm{O}$

\begin{tabular}{lllc}
\hline & \multicolumn{1}{c}{$\begin{array}{c}\text { crystal } \\
\text { data }\end{array}$} & & $\begin{array}{c}\text { data collection } \\
\text { and refinement }\end{array}$ \\
\hline formula & $\left(\mathrm{C}_{3} \mathrm{H}_{7} \mathrm{~N}_{6}{ }^{+}\right)_{4} \cdot\left(\mathrm{H}_{2} \mathrm{PO}_{4}{ }^{1-}\right)_{2} \cdot \mathrm{HPO}_{4}{ }^{2-} \cdot 3 \mathrm{H}_{2} \mathrm{O}$ & data range & $3.03 \leq 2 \theta \leq 42.26^{\circ}$ \\
crystal system & triclinic & no. of data points & 7846 \\
space group & $P \overline{1}($ no. 2$)$ & temperature $(\mathrm{K})$ & 3034 \\
$Z$ & 2 & GoF & 295 \\
$a(\AA)$ & $8.9867(1)$ & $R_{\mathrm{p}}(\%)$ & $7.64(6.35)^{a}$ \\
$b(\AA)$ & $20.8097(2)$ & $R_{\text {wp }}(\%)$ & $5.63(4.34)^{a}$ \\
$c(\AA)$ & $8.9843(1)$ & no. of refined & $7.97(7.36)^{a}$ \\
$\alpha\left({ }^{\circ}\right)$ & $98.1691(9)$ & parameters & \\
$\beta\left({ }^{\circ}\right)$ & & lattice & \\
$\gamma\left({ }^{\circ}\right)$ & $93.4080(5)$ & positional & 186 \\
$V\left(\AA^{3}\right)$ & $93.1424(9)$ & thermal & 4 \\
$d_{\mathrm{m}} / d_{\mathrm{c}}\left(\mathrm{gcm}^{-3}\right)$ & $1656.77(3)$ & texture & 1 \\
& $1.712 / 1.709$ & profile & 19 \\
& & background & 20
\end{tabular}

${ }^{a}$ In parentheses values of R-factors after the full pattern decomposition by the Le Bail method ${ }^{31}$ are given.

\section{Results and Discussion}

Structure Determination of $\mathbf{M}_{4} \mathbf{P}_{3} \cdot \mathbf{3 H}_{2} \mathbf{O}$. The indexing of the experimental powder diffraction pattern (Figure 1) delivered a triclinic cell (Table 1), in view of the unit cell contents likely to be group $P \overline{1}$ with $Z=2$, and with a calculated density (1.709 $\left.\mathrm{g} \mathrm{cm}^{-3}\right)$ that corresponds well with the observed density $\left(d_{\mathrm{m}}=\right.$ $1.712 \mathrm{~g} \mathrm{~cm}^{-3}$ ) as determined at DSM (Geleen, The Netherlands). A number of weak lines could not be indexed, indicating a small amount $(1-3 \%)$ of another crystalline phase.

In the first stages of structure determination, the molecular model of $\mathrm{M}_{4} \mathrm{P}_{3} \cdot 3 \mathrm{H}_{2} \mathrm{O}$ was approximated by four melamine and three phosphate moieties, using the melamine and phosphate geometries as found in MP. ${ }^{2}$ At this stage, all hydrogens and waters were left out. Only after the general packing characteristics (such as melamine ribbons and phosphate layers, see below) became clear, the three waters were included. To position the seven moieties, comprising 42 degrees of freedom in the asymmetric part of the unit cell, the program Organa was used. ${ }^{12 b}$ During the structure determination various soft-distance restraints were used between melamine and phosphate moieties, as suggested by the analysis of common packing elements in other melamine phosphates. ${ }^{2-5}$ The structure determination procedure delivered about 10 different models with the same
$R_{\mathrm{w}}(\sim 10 \%)$ for 86 clusters originating from the 108 lowestangle observed reflections (resolution $\sim 3.1 \AA$ ). All models consisted of alternating melamine and phosphate layers parallel to the $a$ and $c$ axis, with the melamines being packed in layers and forming intralayer infinite ribbons that are stacked almost parallel to each other and to the (10-1) crystallographic plane (Figure 2). However, the melaminelayer packing and the packing of the phosphate moieties relative to the melamine layers differ considerably from the types of melamine-phosphate packing found before. ${ }^{2-5}$

With Organa two types of models were found. In the first type (Figure 2, type I) the phosphate layers were positioned at the $b$-axis coordinates $y \sim 0.0$ and $y \sim 0.5$, while the centers of the melamine layers were at $y \sim 0.25$ and $y \sim 0.75$. In the second type (Figure 2, type II) the $y$-coordinates were interchanged with the phosphates being at $y \sim 0.25$ and $y \sim 0.75$, and the melamine layer centers at $y \sim 0.0$ and $y \sim 0.5$. An analysis pointed out that in the type II models all three nonequivalent orthophosphate moieties were positioned in one of the layers (say, with $y=0.25$ ) since the second one (i.e., $y$ $=0.75$ in this case) is symmetry related in space group $P \overline{1}$. The presence of three orthophosphates in both layers leads to a rather dense phosphate packing with many short contacts 

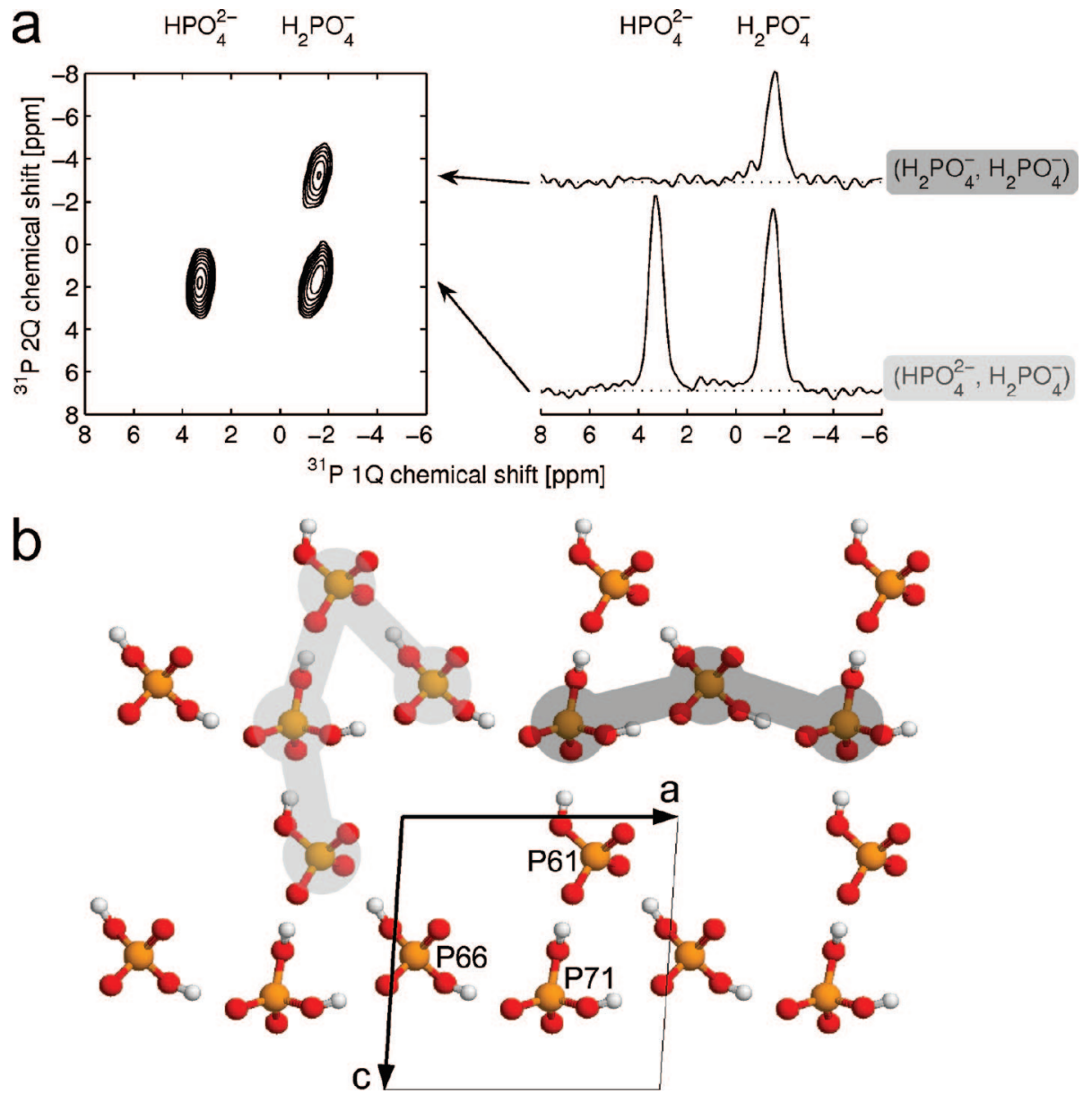

Figure 5. (a) Two-dimensional ${ }^{31} \mathrm{P}$ double-quantum spectrum of $\mathrm{M}_{4} \mathrm{P}_{3} \cdot 3 \mathrm{H}_{2} \mathrm{O}$. On the right, slices through the $2 \mathrm{D}$ spectral peaks parallel to the $\delta_{2}$ dimension are shown with assignment of the individual peaks in the $1 \mathrm{Q}$ and $2 \mathrm{Q}$ dimension being indicated. (b) $\mathrm{Phosphate}$ network in $\mathrm{M}_{4} \mathrm{P}_{3} \cdot 3 \mathrm{H}_{2} \mathrm{O}$. Pairs of one monohydrogen and one dihydrogen phosphate unit are indicated in light gray and pairs of two dihydrogen phosphate units are indicated in dark gray. These pairs give rise to their respective double-quantum peaks in (a).

between all moieties indicating hydrogen bonds. In contrast, in the type I models, with the phosphate layers at $y \sim 0.0$ and $y$ $\sim 0.5$, all symmetry-related orthophosphates belong to the same layer. Thus, to get the correct unit-cell contents, the orthophosphate moieties have to be divided between both phosphate layers. The only possibility to do so (avoiding large voids in the cell) is to situate one orthophosphate in one layer and two in the other. In this way, in the type I models the unit cell contained well-isolated pairs of phosphates in one layer and in the other layer four phosphates, all having short contacts with neighboring phosphates. From a packing point of view, both type I and type II models seemed reasonable, with both packing motifs and bond distances similar to those found in other melamine-phosphate compounds, as discussed below.

The network of phosphate groups has been studied by ${ }^{31} \mathrm{P}$ solid-state NMR. Figure 3 shows the ${ }^{31} \mathrm{P}$ CP-MAS spectra of $\mathrm{M}_{4} \mathrm{P}_{3} \cdot 3 \mathrm{H}_{2} \mathrm{O}$ at two different sample spinning frequencies, (a) 4 and (b) $12 \mathrm{kHz}$. The spectrum shows three resonances, at $+3.1,+1.2$, and $-1.6 \mathrm{ppm}$. The small resonance at $1.2 \mathrm{ppm}$ is attributed to an impurity consisting of an orthophosphate. This probably corresponds to the crystalline impurity observed in the XRPD pattern. A Herzfeld-Berger analysis ${ }^{20}$ of the spinning sideband patterns in Figure $3 \mathrm{a}$ resulted in chemical shift anisotropies of $\left(\delta_{11}, \delta_{22}, \delta_{33}\right)=(56,-15,-32) \pm 2 \mathrm{ppm}$ for the $3.1 \mathrm{ppm}$ (left) resonance and $\left(\delta_{11}, \delta_{22}, \delta_{33}\right)=(53,12,-70)$ $\pm 1 \mathrm{ppm}$ for the $-1.6 \mathrm{ppm}$ peak (right). A comparison with chemical shift anisotropy literature values ${ }^{21}$ shows that the left resonance $(3.1 \mathrm{ppm})$ stems from the phosphorus in a monohy- drogen phosphate group, whereas the right resonance $(-1.6$ ppm) stems from the phosphorus in a dihydrogen phosphate group. Due to the varying CP efficiency for different chemical sites, CP experiments may in general not be interpreted quantitatively. However, a ratio of 1:2 of the number of dihydrogen phosphate sites to the number of monohydrogen phosphate sites in $\mathrm{M}_{4} \mathrm{P}_{3} \cdot 3 \mathrm{H}_{2} \mathrm{O}$ is certainly not consistent with our experimental data, whereas a ratio of $2: 1$ is. The assignment of the two phosphorus resonances is confirmed by the $2 \mathrm{D}$ ${ }^{1} \mathrm{H}-{ }^{31} \mathrm{P}$ HETCOR spectrum of $\mathrm{M}_{4} \mathrm{P}_{3} \cdot 3 \mathrm{H}_{2} \mathrm{O}$ shown in Figure 4b. It shows a single resolved cross-peak between the ${ }^{31} \mathrm{P}$ resonance at $3.1 \mathrm{ppm}$ and a ${ }^{1} \mathrm{H}$ resonance at $14.2 \mathrm{ppm}$, whereas the ${ }^{31} \mathrm{P}$ resonance at $-1.6 \mathrm{ppm}$ has two resolved cross peaks with ${ }^{1} \mathrm{H}$ resonances at 14.0 and $10.3 \mathrm{ppm}$. The ${ }^{1} \mathrm{H}$ chemical shifts indicate that the corresponding $\mathrm{HPO}_{4}{ }^{2-}$ and $\mathrm{H}_{2} \mathrm{PO}_{4}{ }^{-}$ protons are involved in $\mathrm{O}-\mathrm{H} \cdots \mathrm{O}$ hydrogen bonds. At this short contact time LG-CP transfers magnetization from the nearest neighbors and a clearer correspondence to the ratio of $2: 1$ is found for the dihydrogen and monohydrogen phosphate moieties.

To gain further insight into the different proton resonances that can be observed in the single-pulse ${ }^{1} \mathrm{H}$ MAS spectrum shown in Figure $4 \mathrm{a}$ we recorded in addition the $2 \mathrm{D}{ }^{1} \mathrm{H}-{ }^{15} \mathrm{~N}$ HETCOR spectrum of $\left[\mathrm{U}-{ }^{15} \mathrm{~N}\right]-\mathrm{M}_{4} \mathrm{P}_{3} \cdot 3 \mathrm{H}_{2} \mathrm{O}$ shown in Figure $4 c$. The ${ }^{15} \mathrm{~N}$ dimension of the spectrum shows three separated spectral areas: Resonances between -210 and -220 ppm stem from the nonprotonated endocyclic nitrogen sites in the melamine molecules, resonances between -250 and -265 ppm result from the protonated endocyclic $\mathrm{NH}$ groups, and the exocyclic $\mathrm{NH}_{2}$ 

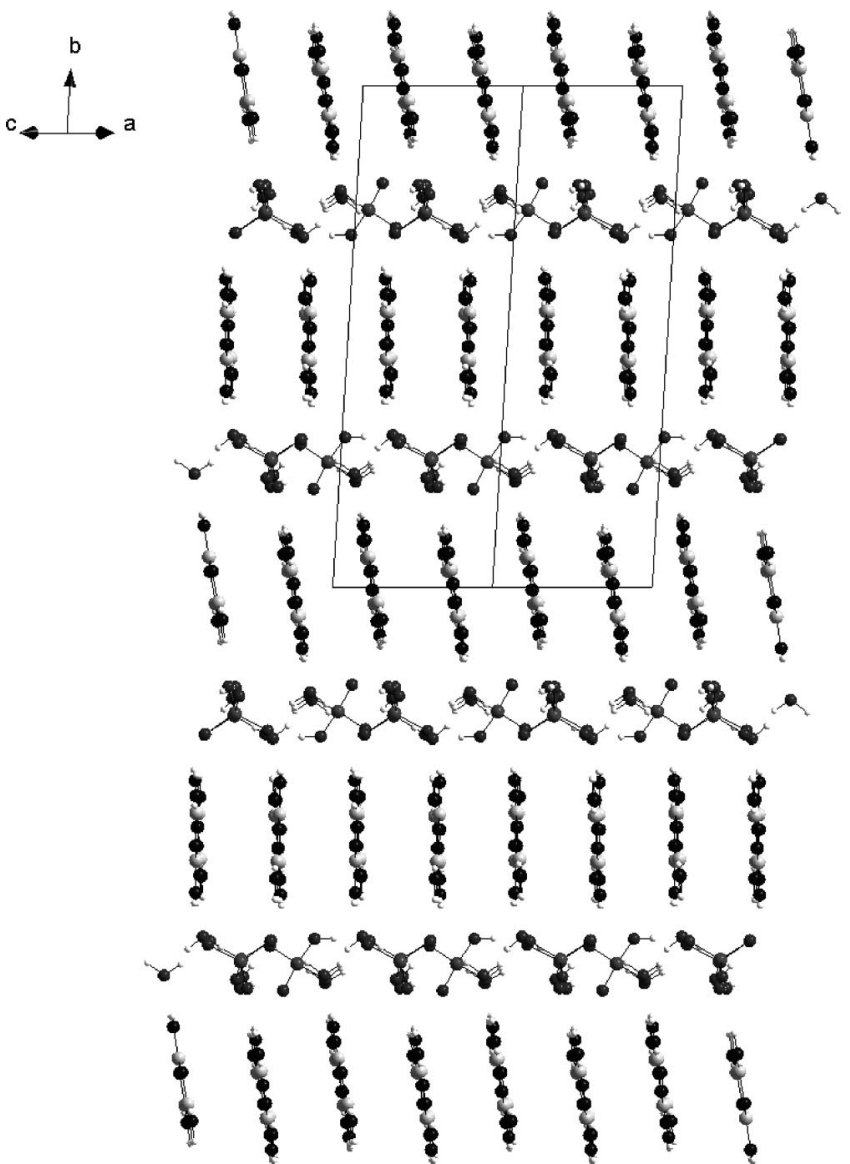

Figure 6. Crystal packing of $\mathrm{M}_{4} \mathrm{P}_{3} \cdot 3 \mathrm{H}_{2} \mathrm{O}$ with the [101] direction perpendicular to the plane of the paper.

groups give rise to the resonances in the range between -270 and $-300 \mathrm{ppm}$. Three well-resolved ${ }^{1} \mathrm{H}-{ }^{15} \mathrm{~N}$ cross-peaks are visible for the $\mathrm{NH}$ sites in the different melamine moieties: The ${ }^{15} \mathrm{~N}$ resonance at $-255.7 \mathrm{ppm}$ is correlated with a ${ }^{1} \mathrm{H}$ resonance at $14.7 \mathrm{ppm}$, the ${ }^{15} \mathrm{~N}$ signal at $259.1 \mathrm{ppm}$ has a cross-peak with the ${ }^{1} \mathrm{H}$ signal at $13.6 \mathrm{ppm}$, and the ${ }^{15} \mathrm{~N}$ peak at $-261.1 \mathrm{ppm}$ is linked with the ${ }^{1} \mathrm{H}$ peak at $12.3 \mathrm{ppm}$. The chemical shift of the different $\mathrm{NH}$ protons point to their involvement in $\mathrm{N}-\mathrm{H} \cdots \mathrm{O}$ hydrogen bonds. The relative peak intensities for these ${ }^{15} \mathrm{~N}$ resonances are 1:1:2 consistent with the $\mathrm{N}-\mathrm{H} \cdots \mathrm{O}$ bond formation of all melamine moieties. The proton resonances of the $\mathrm{NH}_{2}$ groups are strongly overlapping and are located in the range $4-10 \mathrm{ppm}$.

The ${ }^{1} \mathrm{H}-{ }^{31} \mathrm{P}$ and ${ }^{1} \mathrm{H}-{ }^{15} \mathrm{~N}$ HETCOR experiments show that although the spectral region of hydrogen bonded protons in the single-pulse ${ }^{1} \mathrm{H}$ spectrum (Figure 4a) superficially resembles that of the MP sample ${ }^{5}$ there are at least six different hydrogenbonded protons identified in $\mathrm{M}_{4} \mathrm{P}_{3} \cdot 3 \mathrm{H}_{2} \mathrm{O}$.

Besides establishing heteronuclear correlations, it is very useful to determine homonuclear contacts between the different phosphorus sites to elucidate the phosphate network in $\mathrm{M}_{4} \mathrm{P}_{3} \cdot 3 \mathrm{H}_{2} \mathrm{O}$. It has been shown that especially spectra correlating double-quantum coherences (2QC) and single-quantum coherences (1QC) are advantageous in this respect. ${ }^{9}$ In the $2 \mathrm{D}$ ${ }^{31} \mathrm{P} 2 \mathrm{Q}$ spectrum of $\mathrm{M}_{4} \mathrm{P}_{3} \cdot 3 \mathrm{H}_{2} \mathrm{O}$ (Figure $5 \mathrm{a}$ ), two $2 \mathrm{Q}$ peaks can be identified. The $2 \mathrm{Q}$ peak at $\delta_{1}=1.5 \mathrm{ppm}$ in the $2 \mathrm{Q}$ dimension results from the monohydrogen and dihydrogen phosphate sites with chemical shifts $\delta_{2}^{(\mathrm{a})}=3.1 \mathrm{ppm}$ and $\delta_{2}^{(\mathrm{b})}=-1.6 \mathrm{ppm}$ in the 1Q dimension, respectively, indicating that these sites are close in space to each other. The 2Q peak at $\delta_{1}=-3.2 \mathrm{ppm}$ results from two dihydrogen phosphate sites with chemical shift

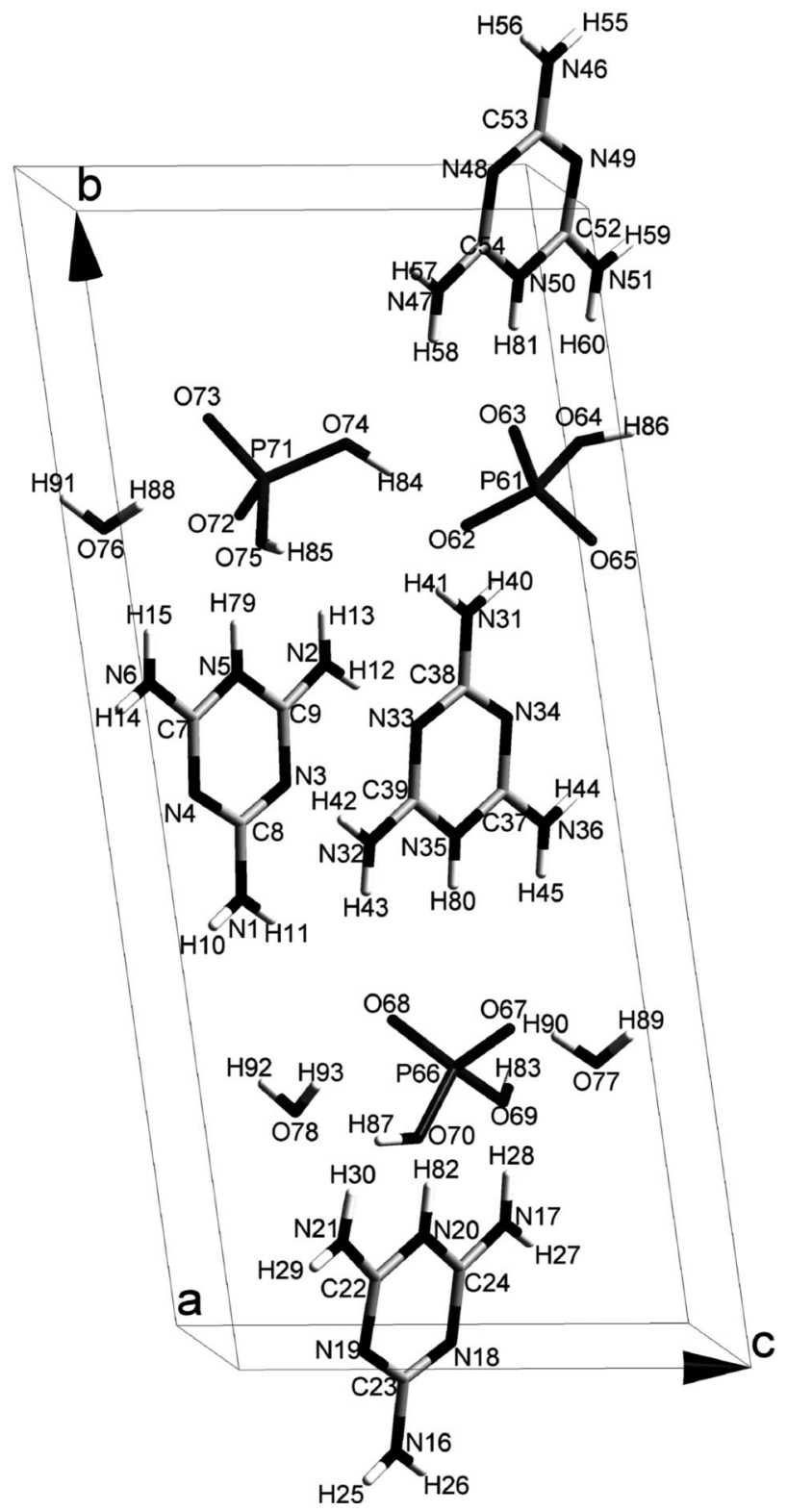

Figure 7. Labeling of the atoms in the asymmetric part of the unit cell of $\mathrm{M}_{4} \mathrm{P}_{3} \cdot 3 \mathrm{H}_{2} \mathrm{O}$.

$\delta_{2}^{(\mathrm{a})}=\delta_{2}^{(\mathrm{b})}=-1.6 \mathrm{ppm}$, indicating that a dihydrogen phosphate site is close to another dihydrogen phosphate site. Figure 5 also shows that there is no peak indicating a close contact between one monohydrogen phosphate site and another monohydrogen phosphate site. On the basis of this information on the phosphate network, it was possible to exclude immediately all type I models from further consideration.

All of the remaining type II models have been refined, but none of them gave satisfactory results. A visual inspection of the sample measured at the ESRF, freshly prepared samples, and the analysis of the corresponding powder-diffraction patterns suggested a significant preferred orientation in the samples, which was difficult to avoid. To get a grip on this phenomenon, samples were prepared with an enhanced preferred orientation (see experimental section) and their diffraction patterns revealed a dominating $(0 n 0)$ zone that, according to our crystal-structure models obtained so far, corresponds to crystallographic planes separating the melamine and phosphate layers (Figure 6). Since attempts to correct for preferred orientation at the stage of refinement did not give any substantial improvement, the 


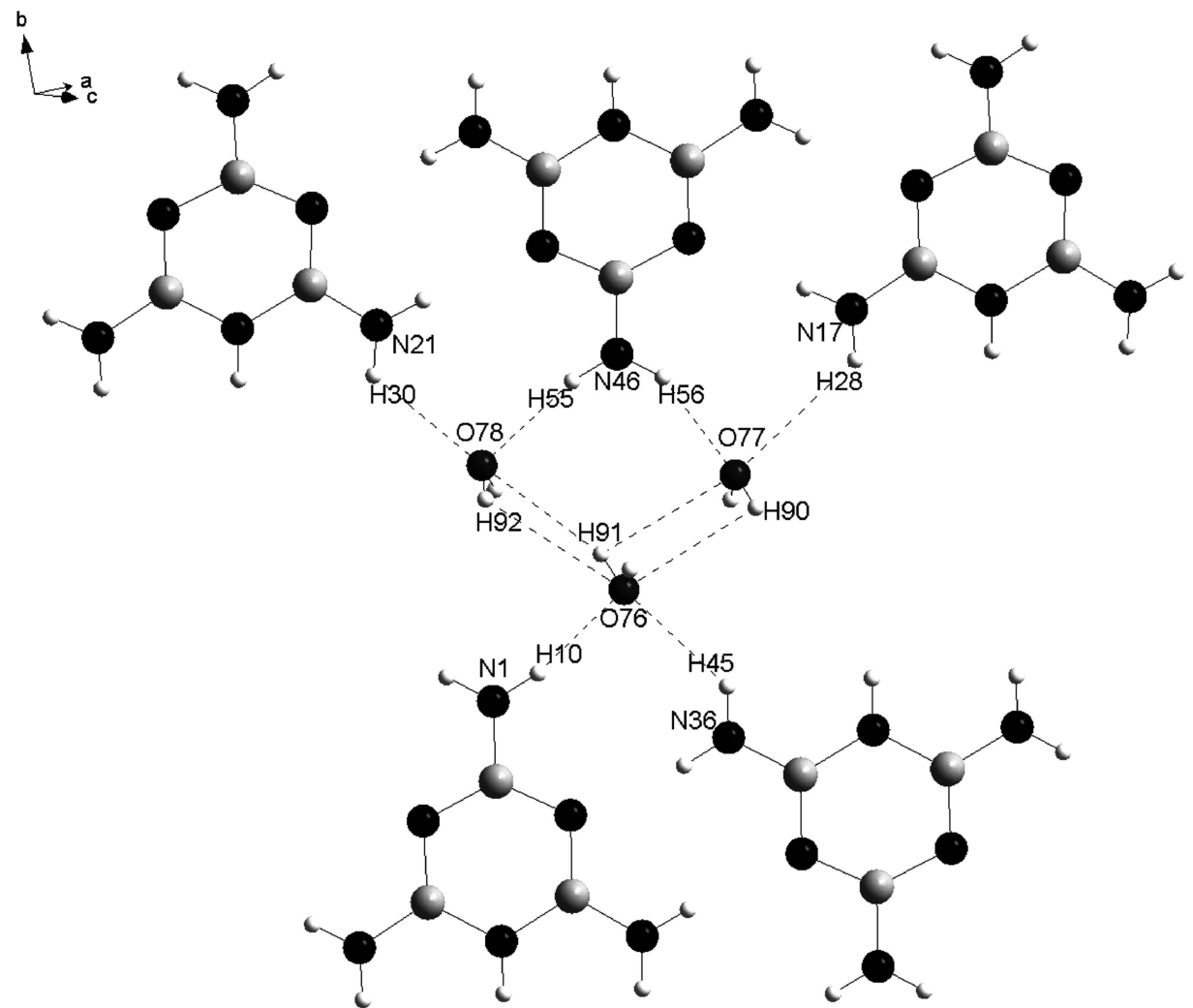

Figure 8. Bonding of the three independent water molecules to the melamines in $\mathrm{M}_{4} \mathrm{P}_{3} \cdot 3 \mathrm{H}_{2} \mathrm{O}$. For the hydrogen bond distances see the Supporting Information.

March-Dollase preferred orientation correction ${ }^{22}$ was implemented in Organa at the structure determination stage in such a way that, given the direction of preferred orientation, the preferred orientation magnitude was an additional variable in the Monte Carlo global minimization.

Starting from each type II model found, a new Monte Carlo run was carried out using the modified program with the [0n0] as preferred-orientation direction. Initially, the preferred-orientation magnitude was set equal to 1.0 (absence of preferred orientation) but during the calculations it refined to the value of $\sim 1.2$ and the $R_{\mathrm{W}}$ for the best model dropped significantly from $10 \%$ to $6 \%$ for the first 107 observed reflections (resolution $\sim 3.1 \AA$ ). Starting with this model, a Rietveld refinement was carried out using the program GSAS ${ }^{13}$ (see Supporting Information for details of the refinement, fractional coordinates and $U_{\text {iso }}$ values of the final structure and hydrogen bonds). Rietveld refinement results are summarized in Table 1. Observed and calculated diffraction patterns show a good correspondence, even at high $2 \theta$ values (Figure 1).

The phosphate network in the final structure of $\mathrm{M}_{4} \mathrm{P}_{3} \cdot 3 \mathrm{H}_{2} \mathrm{O}$ is shown in Figure 5b, viewed along the crystallographic $b$ axis. It consists of a chain of dihydrogen phosphate groups (P66/ 71 ), which are in close contact with each other. The monohydrogen phosphate sites (P61) are positioned in between the dihydrogen phosphate chains. As a result, the monohydrogen phosphate sites are in close contact to the dihydrogen phosphate sites, but not with each other, which is consistent with the ${ }^{31} \mathrm{P}$ 2Q spectrum in Figure 5a.

Crystal Structure of $\mathbf{M}_{\mathbf{4}} \mathbf{P}_{\mathbf{3}} \cdot \mathbf{3 H}_{\mathbf{2}} \mathbf{O}$. The crystal structure of $\mathrm{M}_{4} \mathrm{P}_{3} \cdot 3 \mathrm{H}_{2} \mathrm{O}$ consists of layers of melamine cations alternating with layers of phosphate anions and water molecules (Figure 6 ). The melamine layers are packed as infinite ribbons (Figure 2, type II) with adjacent melamines being linked to each other by means of side-by-side pairs of $\mathrm{N}-\mathrm{H} \cdots \mathrm{N}$ hydrogen bonds
$(\mathrm{N} \cdots \mathrm{N} \sim 3 \AA$; see the Supporting Information) and all molecules lying in one plane. The melamine ribbons are parallel to the [101] direction and stacked along the [10-1] with a melamine intermolecular distance of $\sim 3.2 \AA$, so shorter than the usual distance between $\pi$-aromatic ring systems $(\sim 3.4 \AA)^{23}$, indicating $\pi-\pi$ interactions between the melamines. Each melamine in a ribbon has hydrogen bonds with one or two water molecules $(\mathrm{N} \cdots \mathrm{O} \sim 2.8-3.4 \AA)$ via its exocyclic $\mathrm{NH}_{2}$ groups and with at least three and at most five orthophosphates $(\mathrm{N} \cdot \cdots \mathrm{O}$ $\sim 2.7-3.5 \AA$ ) from two neighboring layers (see Figures 8 and 9 and the Supporting Information). Thus, neighboring anion and cation layers are interconnected by multiple hydrogen bonds that stabilize the structure.

The final crystal structure model (see Figure 7) has two orthophosphate anions and one dianion in the asymmetric part of the unit cell. Within the mixed phosphate-and-water layers, the orthophosphate anions are assembled in infinite chains along the [100] direction, and are cross-linked by orthophosphate dianions in such a manner that the phosphates form a rectangular network in which three water molecules are present. The latter form hydrogen-bonded trimers with $\mathrm{O} \cdots \mathrm{O}$ distances of 3.27 $\AA$ and $2.99 \AA$ (Figure 10).

One of the two nonequivalent anions is hydrogen bonded to four surrounding orthophosphates $(\mathrm{O} \cdots \mathrm{O} \sim 2.5-2.6 \AA)$ and $\mathrm{a}$ water molecule $(\mathrm{O} \cdots \mathrm{O} \sim 2.8-2.9 \AA)$ while the other anion as well as the dianion bind three neighboring orthophosphates $(\mathrm{O} \cdots \mathrm{O} \sim 2.6-2.7 \AA)$ and three and two water molecules $(\mathrm{O} \cdots \mathrm{O} \sim 2.6-3.3 \AA)$ respectively. In this way, both anions are connected to other anions as well as to the dianion. In contrast, the dianion has solely direct bonds to the anions. This difference in phosphate bonding is consistent with the interpretation of the NMR data (Figure 5).

As will be discussed in the next section in more detail, $\mathrm{M}_{4} \mathrm{P}_{3} \cdot 3 \mathrm{H}_{2} \mathrm{O}$ exhibits the typical melamine-phosphate bonding 

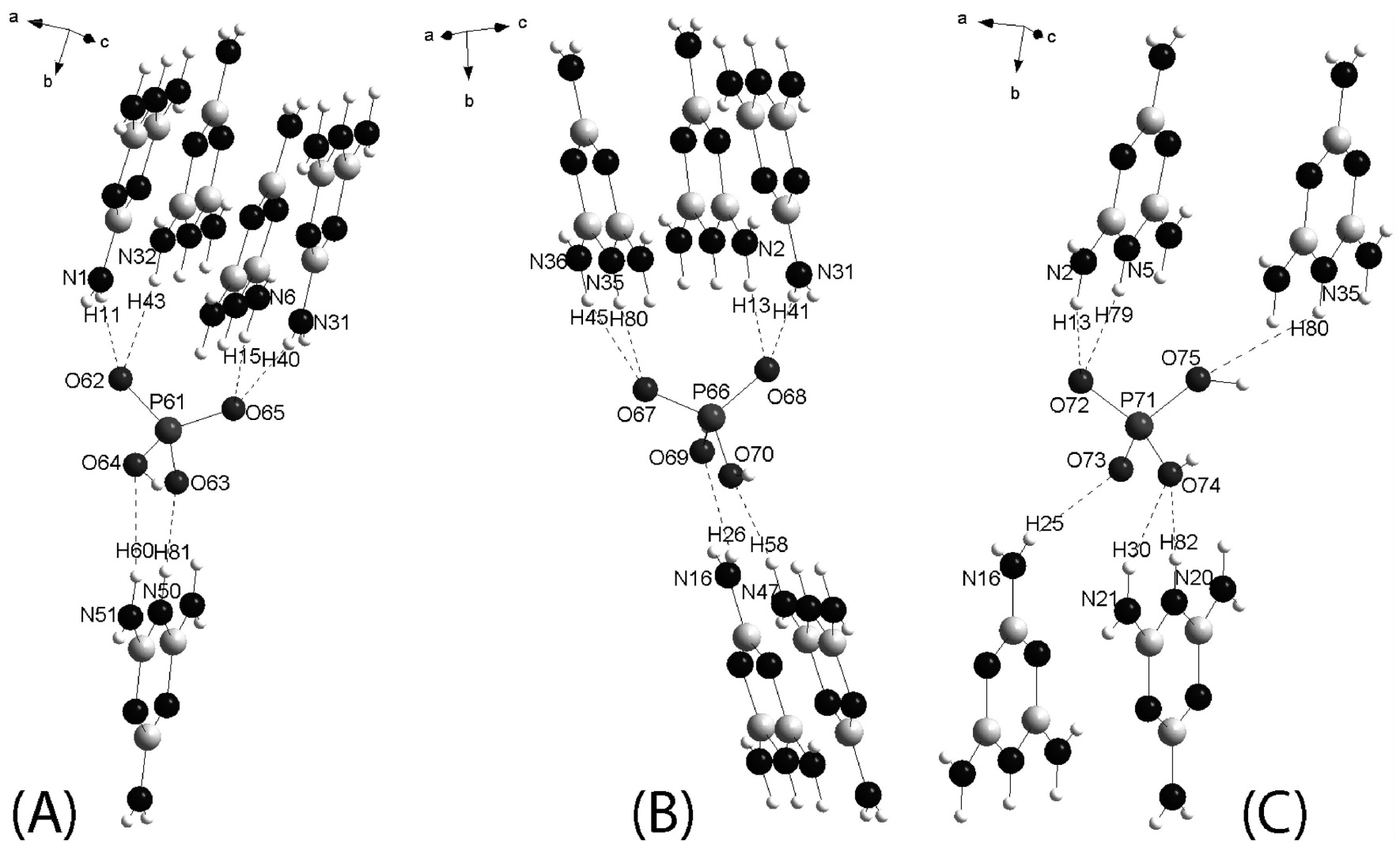

Figure 9. Bonding of the three independent orthophosphates to melamines in $\mathrm{M}_{4} \mathrm{P}_{3} \cdot 3 \mathrm{H}_{2} \mathrm{O}$. For the hydrogen bond distances see the Supporting Information.

pattern in which phosphates are linked via hydrogen bonding to a (protonated) endocyclic nitrogen of melamine $(\mathrm{N} \cdots \mathrm{O} \sim$ 2.7-3.3 $\AA$ ). While the dianion (Figure 9a) and one of the nonequivalent anions (Figure 9c) each participate in only one such bond with one melamine moiety, the other orthophosphate anion (Figure 9b) is shared by three endocyclic nitrogens of melamine moieties from two different layers due to an excess of melamines.

Common Aspects of Crystal Packing in Melamine Phosphates. All of the melamine phosphates of which the crystal structures are known ${ }^{2-5,24}$ have similar structural characteristics. Typically, in these compounds as well as in many other melamine-containing complexes and salts, see reference ${ }^{14}$ and references therein, the melamines are packed in stacks of parallel ribbons. Within each ribbon the melamines are bonded to each other via pairs of hydrogen bonds as described above and the ribbon-stacking distance $(\sim 3.2-3.6 \AA)$ is about the usual distance found in $\pi$-aromatic ring systems $(\sim 3.4 \AA) .{ }^{23}$ In the three investigated melamine phosphates with a melamine-tophosphor (M:P) molar ratio of $1.0\left(\mathrm{MP},{ }^{2,5} \mathrm{MPy},{ }^{3}\right.$ and $\left.\mathrm{Mpoly}^{4}\right)$ zigzag ribbons were observed and in $\mathrm{M}_{4} \mathrm{P}_{3} \cdot 3 \mathrm{H}_{2} \mathrm{O}$ and $\mathrm{M}_{6} \mathrm{P}_{5} \cdot 4 \mathrm{H}_{2} \mathrm{O}^{24}$ straight ribbons. These two ribbon types are both characterized by an infinite repetition of the smallest possible set of three bonded melamines ${ }^{3}$ and they occur in almost all melamine-containing compounds, with only two exceptions known so far: a melamine-imide complex ${ }^{21}$ and a melamine sulfate salt. ${ }^{26}$

The $\mathrm{NH}_{2}$ groups of the melamines in a ribbon are accessible for hydrogen bonding with other (nonmelamine) moieties. Apart from that, each melamine has one endocyclic nitrogen that is not involved in hydrogen bonding with neighboring melamines within the ribbon but this nitrogen does have hydrogen-bond interactions to the phosphate moieties. Via hydrogen bonding of melamine's $\mathrm{NH}_{2}$ groups and endocyclic nitrogens to phosphate moieties $(\mathrm{N} \cdots \mathrm{O}$ distances $\sim 2.7-3.5$ and $\sim 2.5-3.3 \AA$, respectively), the melamine ribbons in melamine phosphates are linked and in this way typical layered structures with alternating melamine and phosphate layers are formed. Depending on the type of melamine ribbon and the stacking, various types of packing are possible in the phosphate layers. While in MP, MPy, and MPoly isolated pairs of phosphate chains occur, in $\mathrm{M}_{4} \mathrm{P}_{3} \cdot 3 \mathrm{H}_{2} \mathrm{O}$ and $\mathrm{M}_{6} \mathrm{P}_{5} \cdot 4 \mathrm{H}_{2} \mathrm{O}$ all phosphates within a layer are interconnected. The oxygen-oxygen distances in the hydrogen bonds between the phosphates range from $\sim 2.5-2.7 \AA$.

The phosphates tend to form hydrogen bonds with all the available endocyclic nitrogens of a melamine ribbon. ${ }^{2-5,24}$ In melamine phosphates with an M:P ratio equal to 1.0, hydrogen transfer takes place one-to-one between a phosphate moiety and an endocyclic nitrogen of a melamine and, as a result, the orthophosphate (or phosphate group in the condensed forms) becomes an anion. In crystal structures with an excess of melamines over phosphates, e.g., $\mathrm{M}_{4} \mathrm{P}_{3} \cdot 3 \mathrm{H}_{2} \mathrm{O}$ and $\mathrm{M}_{6} \mathrm{P}_{5} \cdot 4 \mathrm{H}_{2} \mathrm{O}$, some orthophosphates are shared by endocyclic nitrogens of different melamine moieties. In $\mathrm{M}_{4} \mathrm{P}_{3} \cdot 3 \mathrm{H}_{2} \mathrm{O}$ and $\mathrm{M}_{6} \mathrm{P}_{5} \cdot 4 \mathrm{H}_{2} \mathrm{O}$, hydrogen transfer takes place between phosphate moieties and melamines. The single protonation of all melamines involves a second deprotonation that creates dianionic phosphates. Apparently, the $\mathrm{p} K_{\mathrm{a}}$ for the second deprotonation of orthophosphate acid $(7.21)^{27}$ is low enough to enable the (single) protonation of a second melamine. A double protonation of melamines is not likely since it will destroy the melamine ribbons. Moreover, in comparison with orthophosphates, a single protonated melamine seems to be too acidic $\left(\mathrm{p} K_{\mathrm{a}} \sim 5\right)^{28}$ to accept a second proton.

With an increase of the excess of melamines over phosphates in melamine-phosphate compounds, the amount of oxygens per 


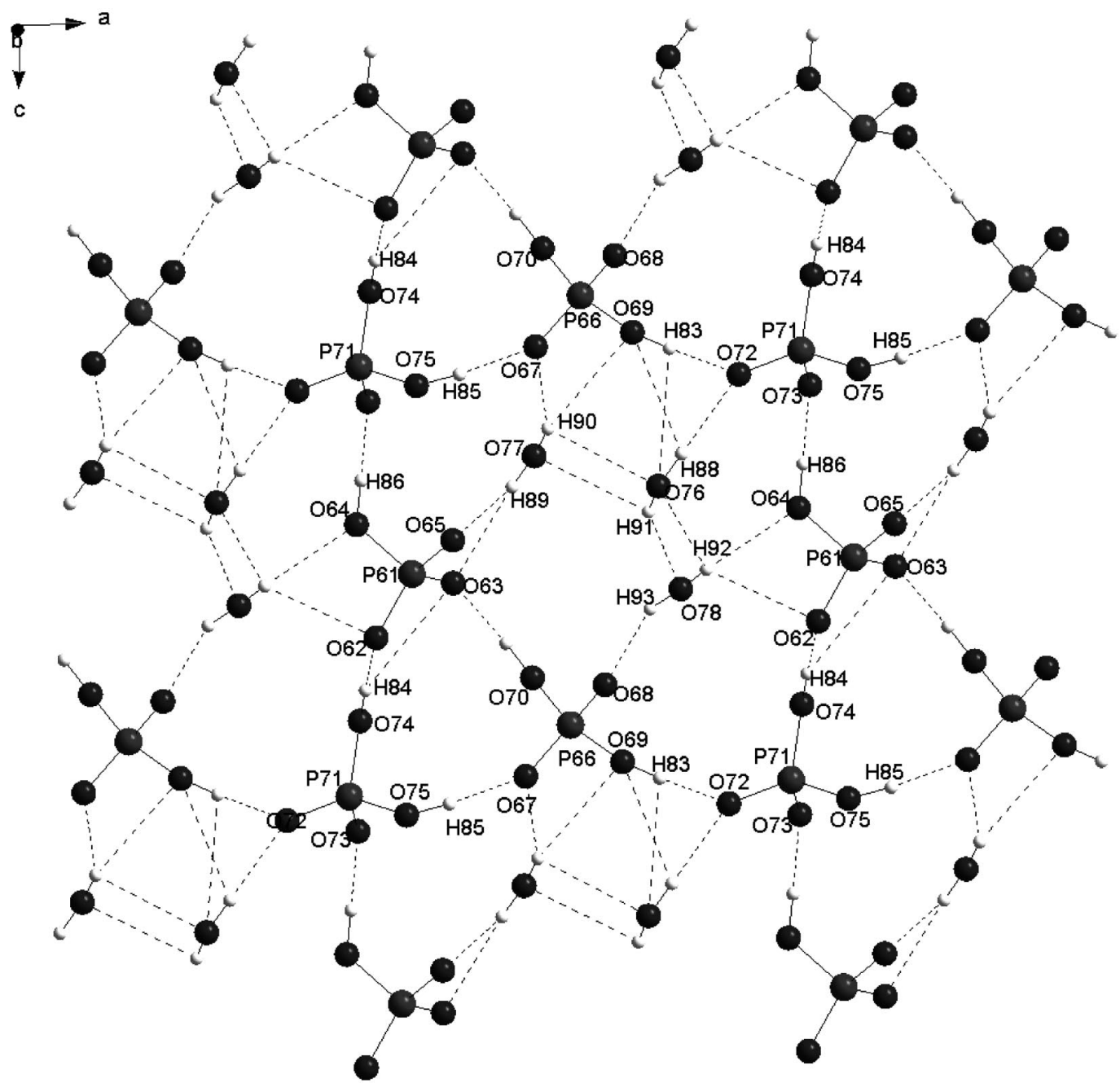

Figure 10. Phosphate-water layer in $\mathrm{M}_{4} \mathrm{P}_{3} \cdot 3 \mathrm{H}_{2} \mathrm{O}$. For the hydrogen bond distances see the Supporting Information.

melamine available for hydrogen-bond formation decreases. The presence of crystalline water in melamine phosphates with an $\mathrm{M}: \mathrm{P}$ ratio $>1$ stabilizes the structure because it provides extra oxygen sites. In $\mathrm{M}_{4} \mathrm{P}_{3} \cdot 3 \mathrm{H}_{2} \mathrm{O}$ and $\mathrm{M}_{6} \mathrm{P}_{5} \cdot 4 \mathrm{H}_{2} \mathrm{O}$ water molecules are bonded to the phosphates $(\mathrm{O} \cdots \mathrm{O} \sim 2.6-3.4 \AA)$ and also to the melamine $\mathrm{NH}_{2}$ groups $(\mathrm{O} \cdots \mathrm{N} \sim 2.8-3.4 \AA)$. In principle, water molecules may also bind to melamine's endocyclic nitrogens, so "closing" this bonding site for phosphate moieties. However, due to the large $\mathrm{p} K_{\mathrm{a}}$ value of water (15.7), hydrogen transfer to a melamine moiety is unlikely in the presence of phosphates. Hydrogen transfer, however, has been observed, for instance, in the structure of bis(melaminium) sulfate dihydrate $(\mathrm{O} \cdots \mathrm{N} \sim 2.5 \AA)$ in which only one orthosulphate moiety is present per two melamine units. ${ }^{26}$ In general, water molecules can be expected to bind to the melamine endocyclic nitrogens in case of a large melamine excess, when a relatively small amount of phosphates is not able to bind all endocyclic nitrogens.

In conclusion we characterized the crystal structure of $\mathrm{M}_{4} \mathrm{P}_{3} \cdot 3 \mathrm{H}_{2} \mathrm{O}$ and compared it with other melamine phosphates to point out the common packing characteristics of these compounds. The structure determination of the compound with 51 degrees of freedom describing 10 independent moieties in the asymmetric part of the unit cell demonstrates the abilities of modern direct-space strategies for structure determination from powder diffraction data in combination with solid-state NMR.
Acknowledgment. The authors acknowledge the ESRF (Grenoble, France) for the opportunity to perform the synchrotron diffraction experiments and Dr. H. Emerich for his help at beamline BM01B (Swiss-Norwegian CRG). They also thank E. J. Sonneveld and W. Molleman for their help in data collection and indexing; Dr. D. J. A. De Ridder, Dr. V. M. Litvinov, Dr. B. Coussens, Dr. A. Braam, and Dr. K. Goubitz for useful discussions and DSM for the synthesis and density measurement of $\mathrm{M}_{4} \mathrm{P}_{3} \cdot{ }_{3} \mathrm{H}_{2} \mathrm{O}$. The authors also acknowledge the technical assistance with the NMR of G. E. Janssen, J. W. G. Janssen, A. A. K. Klaassen, and J. W. M. van Os. This work was supported by DSM (Geleen, The Netherlands), Ciba Speciality Chemicals (Basel, Switzerland), and The Netherlands Foundation for Scientific Research (NWO).

Supporting Information Available: Details of the Rietveld refinement, structural data (CIF file) from the final Rietveld refinement and a Table (SI 1) with potential hydrogen bonds. This material is available free of charge via the Internet at http:// pubs.acs.org.

\section{References and Notes}

(1) Kersjes, J. G.; Kierkels, R. H. M. U. S. Patent, 6653474 B1, 2003.

(2) De Ridder, D. J. A.; Goubitz, K.; Brodski, V.; Peschar, R.; Schenk, H. Helv. Chim. Acta 2004, 87, 1894.

(3) Brodski, V.; Peschar, R.; Schenk, H.; Brinkmann, A.; van Eck, E. R. H.; Kentgens, A. P. M.; Coussens, B.; Braam, A. J. Phys. Chem. B 2004, 108 (39), 15069. 
(4) Brodski, V.; Peschar, R.; Schenk, H.; Brinkmann, A.; van Eck, E. R. H.; Kentgens, A. P. M. J. Phys. Chem. B 2005, 109 (28), 13529.

(5) Brinkmann, A.; Litvinov, V. M.; Kentgens, A. P. M. Magn. Reson. Chem. 2007, 45, S231.

(6) David, W. I. F.; Shankland, K.; Mc Cusker, L. B.; Baerlocher, Ch. Structure Determination from Powder Diffraction Data; Oxford University Press: Oxford, 2002.

(7) Harris, K. D. M. Cryst. Growth Des. 2003, 3 (6), 887.

(8) Harris, K. D. M.; Tremayne, M.; Kariuki, B. M. Angew. Chem. Int. Ed. 2001, 40, 1626.

(9) Feike, M.; Graf, R.; Schnell, I.; Jäger, C.; Spiess, H. W. J. Am. Chem. Soc. 1996, 118, 9631.

(10) Brinkmann, A.; Edén, E.; and Levitt, M. H. J. Chem. Phys. 2000, 112,8539

(11) Visser, J. W. J. Appl. Crystallogr. 1969, $2,89$.

(12) (a) Brodski, V.; Peschar, R.; Schenk, H. J. Appl. Crystallogr. 2003, 36, 239. (b) Brodski, V.; Peschar, R.; Schenk, H. J. Appl. Crystallogr. 2005, 38,688 .

(13) Larson, A. C.; Von Dreele, R. B. General Structure Analysis System (GSAS). Report LAUR 86-748 ; Los Alamos National Laboratory: NM, 1994.

(14) Bennett, A. E.; Rienstra, C. M.; Auger, M.; Lakshmi, K. V.; Griffin, R. G. J. Chem. Phys. 1995, 103, 6951.

(15) Ernst, R. R.; Bodenhausen, G.; Wokaun, A. Principles of Nuclear Magnetic Resonance in One and Two Dimensions; Clarendon, Oxford, 1988.
(16) Samoson, A.; Tuherm, T.; Gan, Z. Solid State NMR 2001, 20, 130. (17) Caravatti, P.; Bodenhausen, G.; Ernst, R. R. Chem. Phys. Lett. 1982, $89,363$.

(18) Levitt, M. H.; Kolbert, A. C.; Bielecki, A.; Ruben, D. J. Solid State NMR 1993, 2, 151.

(19) van Rossum, B.; de Groot, C. P.; Ladizhansky, V.; Vega, S.; de Groot, H. J. M. J. Am. Chem. Soc. 2000, 122, 3465.

(20) Herzfeld, J.; Berger, A. E. J. Chem. Phys. 1980, 73, 6021.

(21) Duncan, T. M. A Compilation of Chemical Shift Anisotropies; Farragut Press: Chicago, 1990.

(22) Dollase, W. A. J. Appl. Crystallogr. 1986, 19, 267.

(23) Pauling, L. The Nature of the Chemical Bond, 3rd ed.; Cornell University Press: Ithaca, 1960; p 262.

(24) Janczak, J.; Perpetuo, G. J. Acta Cryst. Sect C 2002, 58, o455.

(25) Lange, R. F. M.; Beijer, F. H.; Sijbesma, R. P.; Hooft, R. W. W.; Kooijman, H.; Spek, A. L.; Kroon, J.; Meijer, E. W. Angew. Chem. 1997, 109, 1006, Angew. Chem. Int. Ed. Engl. 1997, 36, 969.

(26) Janczak, J.; Perpetuo, G. J. Acta Cryst. Sect C 2001, 57, 1431.

(27) Bjerrum, J. Stability Constants; Chemical Society: London, 1958.

(28) (a) Hirt, R. C.; Schmitt, R. G. Spectrochim. Acta 1958, 12, 127. (b) Morimoto, G. Rev. Phys. Chem. Jpn. 1967, 37 (1), 54. (c) Dudley, J. R. J. Am. Chem. Soc. 1951, 73, 3007. (d) Dixon, J. K.; Woodberry, N. T.; Costa, G. W. J. Am. Chem. Soc. 1947, 69, 599.

\section{JP801985H}

